\title{
HIV Status Disclosure and Uptake of Female Condom among Women Accessing Antiretroviral Therapy Services at a Military Hospital in Lagos, Nigeria
}

\author{
N. E. Harrison ${ }^{1,2 *}$, O. A. Adegbite1, C. U. Agbaim11, O. Nwaiwu ${ }^{3}$, K. E. Oruka1 \\ ${ }^{1}$ Centre for Infectious Disease Clinic, 68 Nigerian Army Reference Hospital Yaba, Lagos, Nigeria \\ ${ }^{2}$ Department of Medicine, 68 Nigerian Army Reference Hospital Yaba, Lagos, Nigeria \\ ${ }^{3}$ Department of Pharmacology, Therapeutics and Toxicology, College of Medicine, University of Lagos, Lagos, Nigeria \\ Email: ^nke1207@yahoo.com
}

How to cite this paper: Harrison, N.E., Adegbite, O.A., Agbaim, C.U., Nwaiwu, O. and Oruka, K.E. (2019) HIV Status Disclosure and Uptake of Female Condom among Women Accessing Antiretroviral Therapy Services at a Military Hospital in Lagos, Nigeria. World Journal of AIDS, 9, 129-141. https://doi.org/10.4236/wja.2019.93010

Received: July 19, 2019

Accepted: September 6, 2019

Published: September 9, 2019

Copyright $\odot 2019$ by author(s) and Scientific Research Publishing Inc. This work is licensed under the Creative Commons Attribution International License (CC BY 4.0).

http://creativecommons.org/licenses/by/4.0/

(c) (†) Open Access

\begin{abstract}
Background: Female condom (FC) has efficiently challenged the increased risk for sexually transmitted infections (STI)/HIV, unwanted pregnancy and promoted self-protection and autonomy among females. However, despite being provided free of charge, the researchers have not observed satisfactory level of demand for FC by the HIV-positive clients at our facility. This study sought to establish the determinants or deterrent factors to the uptake and the use of FC among HIV-infected female clients in an Army hospital, Lagos. Method: A cross-sectional descriptive design was used and 340 interviewees were selected for the survey. Analyses were completed using Epi Info ${ }^{\mathrm{TM}}$ version 7.2.1.0. Association between variables of interests was established using Chi-square. Result: Mean age of the participants was $37.91 \pm 8.33$ years while the median age was 37 . Greater proportion was married (50.5\%), business women $(55.5 \%)$, had at least school certificate $(90.1 \%)$, and had regular sexual partner (84.4\%). Only $69.8 \%$ disclosed their status to their sexual partners, while $79.5 \%$ in turn were informed of their partners' HIV status. Being in marital union, younger age and being aware of partner's HIV status were significantly associated with HIV disclosure $(\mathrm{p}<0.001)$. Contraceptive uptake was $59.8 \%$, while FC use was $5.4 \%$. Most reported limiting factors to FC utilization were non-availability $(22.5 \%)$ and use of male condom by the partner (13.8\%). Conclusion: Suboptimal HIV status disclosure, contraceptive use and very low FC uptake among participants need urgent attention to limit further spread of the virus, STI and prevent unwanted pregnancies.
\end{abstract}




\section{Keywords}

HIV Disclosure, Female Condom, Uptake, ART

\section{Introduction}

Women are more predisposed to contracting sexually transmitted infections (STI) and HIV following unprotected sex than men, and are more affected by consequences of unwanted pregnancies [1]. This has been attributed to the dominating role of men, culture of women submission and passivity in sexual negotiation [2]. As a result, women often find it difficult to negotiate for their own safety during sexual activities.

However, the advent of female condom (FC) has efficiently challenged this norm. With this, women are able to protect themselves without the consent of their male partners. Consequently, FC is seen as a tool for women's empowerment that enables them to exercise control over self-protection, and this invariably increases their sexual confidence and autonomy [3].

Till date, FC remains the only female-initiated means of contraception and STI prevention [4]. It has been established that among other barrier methods, FC is comparably efficacious for preventing pregnancies and equally effective in protecting against STI [5] [6]. A consistent use has been found to be highly protective against vaginal trichomoniasis [7]. It can lower annual HIV risk by more than $90 \%$ when women have sexual intercourse with HIV positive males [8].

Besides its benefits, FC has demonstrated better acceptability among its users in several settings. A randomised control trial reported a preferential and higher usage of FC than male condom among sex workers [9]. Thus better compliance and success in using it as a means of contraception and reducing incidence of common STI among women could be achieved. Interestingly, studies have also documented its acceptability among men as a result of its less interference with sexual sensations compared with male condom. In a study done in Zimbabwe in which sex workers, urban women attending family planning clinic and rural women were recruited as participants, over $50 \%$ of women in these three groups and their partners expressed greater satisfaction and preference for FC over male condom as against $10 \%$ that did not like it [10]. A similar study done in a New York City hospital, where respondents were drawn from among the hospital staff and patients, reported that $73 \%$ of the women and $44 \%$ of their partners indicated higher preference for FC over male condom [11]. It can therefore be said that FC is a better substitute for male condom and more acceptable among sexual partners. FC use may therefore be invaluable to safer sexual practices, birth control, and curbing HIV spread, especially in countries that are worse affected by HIV menace.

Nigeria has the second largest number of people living with HIV (PLWH), and about $80 \%$ of new infection is acquired via heterosexual route [12] [13]. 
High prevalence of STI is also evident. Several isolated studies have, at various times, demonstrated high STI prevalence among different population groups, but more importantly, higher rate has been observed among PLWH [14] [15] [16] [17] [18]. STI has been known to facilitate both transmission and acquisition of HIV. Hence, promoting FC use among PLWH will offer benefits of self-protection, contraception and limit HIV transmission. In many urban settings, extant studies have reported some level of awareness about FC, as well as the challenge of low utilization among HIV infected and uninfected individuals [19] [20]. It may be speculated that disclosure of HIV status to sexual partners will influence FC use among HIV positive women.

However, sexual partners of PLWH need to be protected through voluntary disclosure. Disclosure is a potent preventive strategy and should be seen as a social and legal responsibility of HIV positive individuals to their partners [21]. It is recommended that women disclose their HIV status to family, or friends, but most importantly, a stable partner [22]. This has been linked to improved health outcomes for PLWH [23] and will encourage safe sex practices among partners, especially in settings where heterosexual sex is becoming a common means of HIV transmission among couples [24].

Nevertheless, stigma and discrimination are common experiences among HIV positive women. They are often referred to as "vectors", "diseased" or "prostitutes"; whereas, HIV positive men face less of such stigmatizing encounters [24] [25] [26]. This hinders voluntary status disclosure by women to their sexual partners. Nonetheless, recommendation of couple HIV counselling which promotes provider-facilitated disclosure, counselling on safer sex practices and linkage to care when one of the partners is tested positive can mitigate the negative impact of stigma and discrimination on disclosure among sexual partners [27] [28].

From the foregoing, it can be said that some HIV positive women do find it difficult to disclose their status and this may affect safe sex practices like the use of FC with their partners. Similar to observations made in other studies [19] [20], in our clinic, we have not observed any satisfactory level of demand for FC by the clients who come to access Antiretroviral therapy (ART) services despite being provided free. There is also dearth of studies among PLWH that specifically address acceptability and barriers related to the uptake of this invention, especially in settings where neither availability nor cost is a concern. We are therefore seeking to establish the prevalence of HIV status disclosure and the determinants or deterrent factors affecting the uptake and the use of FC among clients attending our ART clinic.

\section{Study Design and Method}

This was a cross-sectional, descriptive, questionnaire-based survey.

\subsection{Study Setting}

The study was conducted at a Military Hospital in Yaba, Lagos. This is located in 
Yaba Local Council Development Area of Lagos State. The area lies in south western Nigeria, in the Gulf of Guinea, west of the Niger River delta. It is located on the longitude $3^{\circ} 24^{\prime} \mathrm{E}$ and latitude $6^{\circ} 27^{\prime} \mathrm{N}$. The monthly rainfall varies from the lowest of $35 \mathrm{~mm}$ ( 1.5 inches) in January to the highest of $300 \mathrm{~mm}$ (12 inches) in July [29]. The hospital is a 500-bed capacity facility and operates as a tertiary centre. It runs daily adult HIV clinic at its Centre for Infectious Disease (CID) Clinic with average daily clinic attendance of 100 clients.

\subsection{Study Participants}

Our participants were drawn from among the women who were living with HIV and were receiving treatment at CID. Participants were recruited when they came for their routine clinical visits and drug pick up. Inclusion criteria for selection were: adult (age 18 years and above), enrolment for care at the study site, and able and willing to voluntarily consent. Identified potential participants who were either below 18 years or declined consent were excluded from the study.

All eligible and consenting participants were conveniently selected until the sample size, which was determined using appropriate formula was reached. Participants were recruited daily by three trained research assistants from March 2017 to July 2017. Data was collected using pretested self-administered structured and semi-structured questionnaire-designed following relevant literature search.

\subsection{Statistical Analyses}

Descriptive statistics was used to summarize the major findings in the study while associations between variables of interests were sought using chi square. $\mathrm{P}$-value of 0.05 and below was considered statistically significant. Data analyses were completed by means of Epi Info ${ }^{\mathrm{TM}}$ for windows, version 7.2.1.0, and results presented using tables, charts and texts as applicable.

\subsection{Ethical Approval and Consent}

Approval was obtained for this study from the Research and Ethical Committee of a Military Hospital in Yaba Lagos, Nigeria. Consent was also obtained from every volunteered participant and confidentiality of the participants' personal information was guaranteed by anonymizing the questionnaires.

\section{Result}

We distributed 340 questionnaires, out of which 334 were returned and one was invalidated due to improper filling of the questionnaire. Therefore, 333 representing $98 \%$ were included in these analyses.

The mean age of the participants was $37.91 \pm 8.33$ years while the median age was 37. The oldest among the respondents was 73 years and the youngest, 17 years. Over half $(50.5 \%)$ of the participants were in marital union, majority (91.9\%) were Christians and yet more than half (55.5\%) were business women. 
Moreover, $90.1 \%$ of the respondents had completed at least secondary education. Furthermore, majority $(297 ; 84.4 \%)$ of the respondents had regular sexual partner, amongst which only $69.8 \%$ disclosed their status to their sexual partners, while $79.5 \%$ in turn knew the status of their partners (Table 1 ).

Table 1. Socio-demographic characteristics of the participants $\mathrm{N}=333$.

\begin{tabular}{|c|c|c|c|}
\hline Variables & Responses & Proportion & Percentage \\
\hline \multirow{6}{*}{ MARITAL STATUS } & Married & 168 & 50.5 \\
\hline & Single & 86 & 25.8 \\
\hline & Widowed & 37 & 11.1 \\
\hline & Separated/Divorced & 20 & 6.0 \\
\hline & Cohabiting & 16 & 4.8 \\
\hline & Not Specified & 6 & 1.8 \\
\hline \multirow{4}{*}{ Religion } & Christianity & 306 & 91.9 \\
\hline & Islam & 21 & 6.3 \\
\hline & Not Specified & 6 & 1.8 \\
\hline & Business & 185 & 55.5 \\
\hline \multirow{5}{*}{ Occupation } & Public/Civil Servant & 87 & 26.2 \\
\hline & Unemployed/House Wife & 35 & 10.5 \\
\hline & Schooling & 14 & 4.2 \\
\hline & Not Specified & 12 & 3.6 \\
\hline & $\leq 25$ Years & 16 & 4.8 \\
\hline \multirow{5}{*}{$\begin{array}{c}\text { Age } \\
\text { Mean: } 37.91 \pm 8.33 \text { Years }\end{array}$} & 26 - 35 Years & 128 & 38.3 \\
\hline & 36 - 45 Years & 142 & 42.5 \\
\hline & 46 - 55 Years & 38 & 11.4 \\
\hline & 56 - 65 Years & 8 & 2.4 \\
\hline & 66 Years and above & 2 & 0.6 \\
\hline \multirow{5}{*}{ Educational Level } & Tertiary & 135 & 40.5 \\
\hline & Secondary & 165 & 49.6 \\
\hline & Primary & 24 & 7.2 \\
\hline & None & 2 & 0.6 \\
\hline & Not Specified & 7 & 2.1 \\
\hline \multirow{3}{*}{ Has Regular Sexual Partner(s) } & Yes & 297 & 84.4 \\
\hline & No & 33 & 14.7 \\
\hline & Not Specified & 3 & 0.9 \\
\hline \multirow{2}{*}{$\begin{array}{l}\text { Disclosed HIV Status to Sexual } \\
\text { Partner }(\mathrm{N}=297)\end{array}$} & Yes & 204 & 69.8 \\
\hline & No & 93 & 30.2 \\
\hline \multirow{4}{*}{$\begin{array}{l}\text { HIV Status of Regular Sexual } \\
\quad \text { Partner(s) }(\mathrm{N}=297)\end{array}$} & Negative & 148 & 49.9 \\
\hline & Positive & 88 & 29.6 \\
\hline & Don’t Know & 55 & 18.5 \\
\hline & Not Specified & 6 & 2.0 \\
\hline
\end{tabular}


Chi square revealed that marital status, age group, knowledge of partner status significantly affected HIV disclosure with p-value less than 0.001 each. In other words, being in a marriage or cohabiting with a partner was associated with status disclosure to such partners, likewise knowledge of partner HIV status, while participants in the extremes of age were less likely to disclose their status to their partners. Nonetheless, neither educational level nor religion seems to affect disclosure (Table 2).

Also, regarding the contraceptive methods that were being or had been used by the respondents, male condom was the most frequently employed, followed by practice of safe period calculation and withdrawal method (coitus interruptus). These were followed by use of oral contraceptive pills and female condom which was practiced by $5.4 \%$ each of the respondents, and use of injectables (Depo Provera), among others. Surprisingly however, $40.2 \%$ of the respondents never employed any family planning option (Figure 1). In addition, most (326; 97.9\%) of the respondents perceived the need for self-protection during sex despite already being infected with HIV, 4 (1.2\%) did not, while 3 respondents $(0.9 \%)$ did not respond. For those who felt the need for self-protection, reasons provided (Figure 2) include: to prevent STI (44.7\%), to prevent HIV spread $(37.2 \%)$, to protect their immunity $(9.3 \%)$, to avoid contacting other strains of

Table 2. Factors affecting HIV status disclosure.

\begin{tabular}{|c|c|c|c|}
\hline \multirow[t]{3}{*}{ Factors } & \multicolumn{2}{|c|}{ Disclosure } & \multirow[t]{3}{*}{ p-value } \\
\hline & Yes & No & \\
\hline & n (\%) & n (\%) & \\
\hline \multicolumn{4}{|l|}{ Partner HIV status } \\
\hline Negative & $109(73.6)$ & $39(26.4)$ & \\
\hline Positive & $84(95.4)$ & $4(4.6)$ & $<0.001$ \\
\hline Not known & $11(20.0)$ & $44(80.0)$ & \\
\hline \multicolumn{4}{|l|}{ Age group in years } \\
\hline$\leq 25$ & $3(25.0)$ & $9(75.0)$ & \\
\hline $26-35$ & $84(70.6)$ & $35(29.4)$ & \\
\hline $36-45$ & $98(76.6)$ & $30(25.4)$ & $<0.001$ \\
\hline $46-55$ & $15(50.0)$ & $15(50.0)$ & \\
\hline $56-65$ & $4(57.1)$ & $3(42.9)$ & \\
\hline 66 and above & $0(0.00)$ & $1(100.0)$ & \\
\hline \multicolumn{4}{|l|}{ Marital status } \\
\hline Married & $164(91.1)$ & $16(8.9)$ & \\
\hline Cohabiting & $6(85.7)$ & $1(14.3)$ & \\
\hline Single & $24(34.8)$ & $45(65.2)$ & $<0.001$ \\
\hline Separated/divorced & $3(23.1)$ & $10(76.9)$ & \\
\hline Widowed & $7(25.9)$ & $20(74.1)$ & \\
\hline \multicolumn{4}{|l|}{ Educational level } \\
\hline None & $1(50.0)$ & $1(50.0)$ & \\
\hline Primary & $10(50.0)$ & $10(50.0)$ & \\
\hline Secondary & $105(67.7)$ & $50(32.3)$ & 0.105 \\
\hline Tertiary & $86(74.8)$ & $29(25.2)$ & \\
\hline \multicolumn{4}{|l|}{ Religion } \\
\hline Christian & $189(69.2)$ & $84(30.8)$ & \\
\hline Islam & $14(66.7)$ & $7(33.3)$ & 1.000 \\
\hline
\end{tabular}




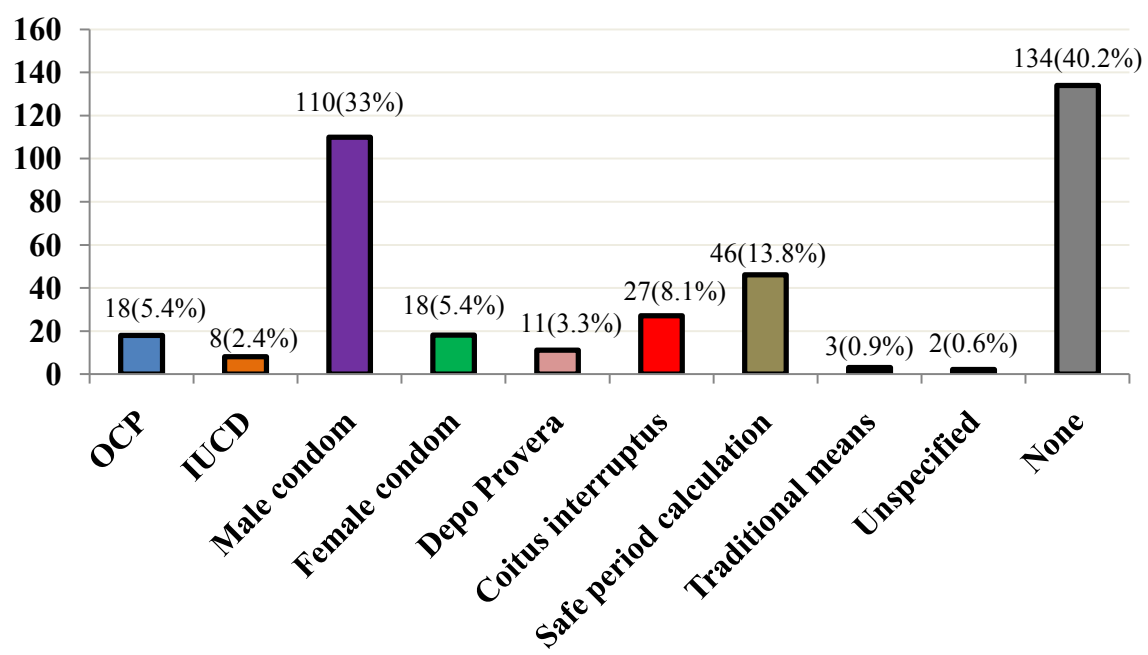

Figure 1. Methods of contraception used by the respondents.
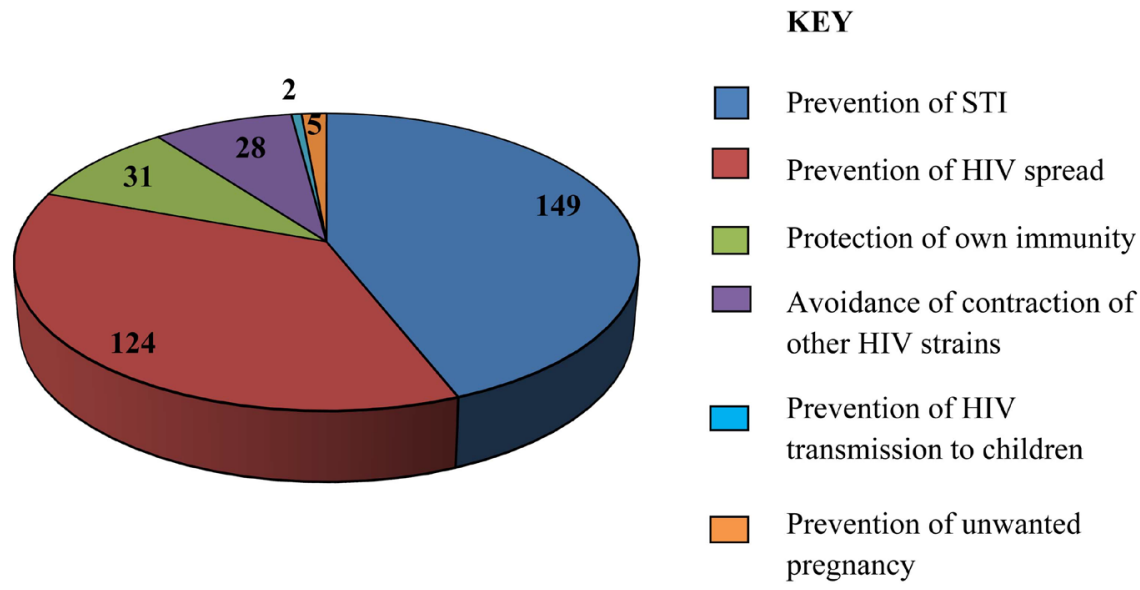

Figure 2. Perceived reasons for self-protection despite being infected with HIV among the respondents (multiple responses).

HIV (8.4\%), to avoid transmission of HIV to children $(0.6 \%)$ and to avoid unwanted pregnancy $(1.5 \%)$.

Knowledge and use of female condom

Majority of the respondents have heard of FC, 312 (93.7\%), but only 199 (59.8\%) have seen female condom. The percentage further reduced to $16.8 \%$ when asked about usage of female condom. The use of female condom was not significantly affected by factors like educational level, partner status among others (Table 3).

Non availability of condoms was the highest reason given as limiting factors for non-usage of female condoms, followed by reliance on the partner's use of male condom, and partners dislike for female condom among others (Table 4).

Moreover, use of male condom was the most frequently identified means to prevent STI transmission among the participants, followed by use of male condom, practicing sexual abstinence, not sharing underwear, avoiding sharing of toilets, among others (Figure 3). 
Table 3. Factors affecting female condom use.

\begin{tabular}{|c|c|c|c|}
\hline \multirow[t]{3}{*}{ Factors } & \multicolumn{2}{|c|}{ Condom Use } & \multirow[t]{3}{*}{ p-value } \\
\hline & Yes & No & \\
\hline & N (\%) & N (\%) & \\
\hline \multicolumn{4}{|l|}{ Partner HIV status } \\
\hline Negative & $25(16.9)$ & $123(83.1)$ & \\
\hline Positive & $20(22.7)$ & $68(77.3)$ & 0.490 \\
\hline Don't know & $9(16.7)$ & $45(83.3)$ & \\
\hline \multicolumn{4}{|l|}{ Age group in years } \\
\hline$\leq 25$ & $0(0.0)$ & $16(100.0)$ & \\
\hline $26-35$ & $22(17.3)$ & $105(82.7)$ & \\
\hline $36-45$ & $28(20.0)$ & $112(80.0)$ & 0.439 \\
\hline $46-55$ & $5(13.5)$ & $32(86.5)$ & \\
\hline $56-65$ & $1(12.5)$ & $7(87.5)$ & \\
\hline 66 and above & $0(0.00)$ & $1(100.0)$ & \\
\hline \multicolumn{4}{|l|}{ Marital status } \\
\hline Married & $33(18.3)$ & $147(81.7)$ & \\
\hline Cohabiting & $1(14.3)$ & $6(85.7)$ & \\
\hline Single & $14(16.1)$ & $73(83.9)$ & 0.893 \\
\hline Separated/divorced & $3(15.8)$ & $16(84.20$ & \\
\hline Widowed & $4(11.4)$ & $31(88.6)$ & \\
\hline \multicolumn{4}{|l|}{ Educational level } \\
\hline None & $0(0.0)$ & $2(100.0)$ & \\
\hline Primary & $3(12.5)$ & $21(87.5)$ & \\
\hline Secondary & $32(19.4)$ & $133(80.6)$ & 0.612 \\
\hline Tertiary & $20(15.5)$ & $113(85.0)$ & \\
\hline \multicolumn{4}{|l|}{ Religion } \\
\hline Christian & $54(17.8)$ & $250(82.2)$ & \\
\hline Islam & $2(9.5)$ & $19(90.5)$ & 0.503 \\
\hline \multicolumn{4}{|l|}{ HIV status disclosure } \\
\hline Yes & $40(19.6)$ & $164(80.4)$ & \\
\hline No & $15(16.3)$ & $77(83.7)$ & 0.606 \\
\hline
\end{tabular}

Table 4. Factors limiting female condom use $(\mathrm{N}=333)$.

\begin{tabular}{ccc}
\hline Factors & Yes & No \\
$\mathbf{n}(\%)$ & $75(22.5)$ & $258(77.5)$ \\
Non availability & $46(13.8)$ & $287(86.2)$ \\
My partner is using male condom & $38(11.4)$ & $295(88.6)$ \\
My partner does not like it & $25(7.5)$ & $308(92.5)$ \\
Difficulty with insertion & $16(4.8)$ & $317(95.2)$ \\
I do not enjoy it & $8(2.4)$ & $325(97.6)$ \\
Not for a decent person's usage & $6(1.8)$ & $327(98.2)$ \\
It is too cumbersome & &
\end{tabular}

\section{Discussion}

Most of our respondents fell within child bearing age (median age $=37$ years), and expectedly, majority (84.4\%) have regular sexual partners. However, about one third $(30.2 \%)$ concealed their HIV status from their sexual partners (Table 1). This is pointing to the persistence of depressing fear from anticipated stigma and discrimination and other factors that hinder disclosure in Nigeria setting where people find it difficult to willingly disclose their status. This study establishes that disclosure is positively influenced by age (extremes of age are less 


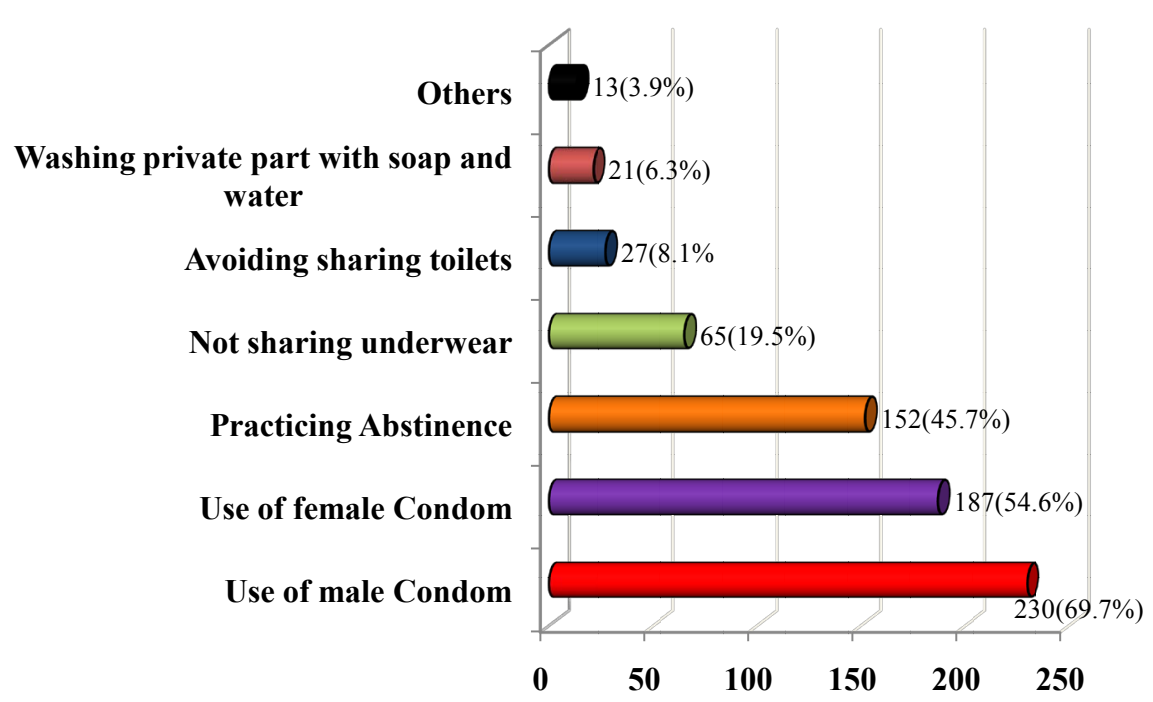

Figure 3. Respondents' perceived strategies for STI prevention (multiple responses).

likely to disclose), marital status (being in a marriage or cohabiting with a partner tends to facilitate disclosure to such partners) as well as knowledge of partner HIV status. These are all statistically significant; but neither educational level nor religion seems to affect disclosure (Table 2). The untoward consequences of non-disclosure may include engaging in condom-less sex with previously uninfected and unaware partners. This may engender and perpetuate HIV spread which poses a great challenge to halting HIV epidemics in Nigeria. Similarly, Kalichman et al. [30] in Atlanta, Georgia observed that two-thirds of HIV infected-participants who had unprotected sex with HIV-negative/unknown status partners had not disclosed their HIV status. About half of the participants indicated that they were in discordant relationship. This is similar to studies in Europe and Uganda were more than half of their participants were in sero-discordant relationship [31] [32].

This study noted low contraceptive practice among our participants. Similarly, Nieves et al. [32] in rural Uganda observed that less than half of women living with HIV use contraceptive and most of them solely relied on male condoms. Also, male condom predominance as contraceptive method was noted in our own study too. This could be due to erroneous belief. Joshi et al. [33] observed in Mumbai that a large number of HIV infected women (42.7\%) considered contraceptives other than condoms harmful to use due to their HIV status. There is therefore need for expansion of access to more female-controlled contraceptive methods, especially as it has been reported that a higher proportion of HIV-positive women are more likely to have unintended pregnancies and a desire not to have more children [32] [34].

However, it was expected that women of this status would understand the implications and dangers of STI to their health and others, but this study revealed that they were not demonstrating enough of expected carefulness in their sexual health. As similarly revealed by a study, $44 \%$ of participants had engaged in un- 
protected sex with HIV-negative/unknown status sex partners and those participants experienced higher rates of STI symptoms and diagnoses [30].

Although almost every participant realised the need for self-protection during sex (97.9\%), practice of it is abysmally poor among our clients. This study demonstrated that only $16.8 \%$ of participants have ever used FC for their own protection during sex. As noted in this study, none of factors like age, educational level, religion, marital status, disclosure or knowledge of partner HIV status appears to significantly affect condom use during sex (Table 3 ).

It can be said that good understanding of the importance of self-protection among HIV infected women is still seriously lacking. Shift in the current paradigm is desirable to curb further HIV transmission or acquisition of STI, as well as to prevent contracting resistant HIV that may lead to poor viral suppression and treatment failure in those who are already virally suppressed. Besides, FC is a device that empowers women to be in charge of their own protection during sex against STI, HIV and even unwanted pregnancy.

Poor FC use has been attributed to poor availability. In our own centre, FC is usually available. This contradiction may therefore mean that poor information dissemination and/or information assimilation had impaired the FC uptake, and hence, its use. This finding calls for a need for continuous effort to provide information regularly on what can improve patients' health and limit chance of further HIV transmission. This becomes necessary especially because the healthcare facility remains the main source of information to majority of the patients $(67.3 \%)$ as noted in the study.

\section{Conclusion}

Suboptimal HIV status disclosure, contraceptive use and the very low uptake of FC among the participants also need urgent attention to limit further spread of the virus, contraction of STI and unwanted pregnancy. Scaling up awareness of the availability of free FC at the clinics and continuous education of HIV positive women and their partners to increase awareness on the importance of consistent condom utilization during counselling is also advocated. Additionally, efforts should be geared towards empowering women on self-protection during sex through FC use, disclosure of HIV status to partners and consistent condom use among the partners.

\section{Conflicts of Interest}

The authors declare no conflicts of interest regarding the publication of this paper.

\section{References}

[1] Cecil, H., Perry, M.J., Seal, D.W. and Pinkerton, S.D. (1998) The Female Condom: What We Have Learned Thus Far. AIDS and Behaviour, 2, 241-256. https://doi.org/10.1023/A:1022141918771 
[2] Shervington, D.O. (1993) The Acceptability of the Female Condom among Low Income African-American Women. Journal of the National Medical Association, 85, 341-347.

[3] Gollub, E.L. (2000) The Female Condom: Tool for Women Empowerment. American Journal of Public Health, 90, 1377-1381. https://doi.org/10.2105/AJPH.90.9.1377

[4] Hoffman, S., Mantell, J., Exner, T. and Stein, Z. (2004) The Future of the Female Condom. Perspectives on Sexual and Reproductive Health, 36, 120-126. https://doi.org/10.1363/3612004

[5] Farr, G., Gabelnick, H., Sturgen, K. and Dorflinger, L. (1994) Contraceptive Efficacy and Acceptability of the Female Condom. American Journal of Public Health, 84, 1960-1964. https://doi.org/10.2105/AJPH.84.12.1960

[6] French, P.P., Latka, M., Gollub, E.L., Rogers, C., Hoover, D.R. and Stein, Z.A. (2003) Use-Effectiveness of the Female versus Male Condom in Preventing Sexually Transmitted Disease in Women. Journal of the American Sexually Transmitted Diseases Association, 30, 433-439. https://doi.org/10.1097/00007435-200305000-00010

[7] Soper, D.E., Shoupe, D., Shangold, D.A., Shangold, M.M., Gutmann, J. and Mercer, L. (1993) Prevention of Vaginal Trichomoniasis by Compliant Use of the Female Condom. Journal of the American Sexually Transmitted Diseases Association, 20, 137-139. https://doi.org/10.1097/00007435-199305000-00003

[8] Trussell, J., Sturgen, K., Strickler, J. and Dominik, R. (1994) Comparative Contraceptive Efficacy of the Female Condom and Other Barrier Methods. Family Planning Perspectives, 26, 66-72. https://doi.org/10.2307/2136004

[9] Fontanet, A.L., Saba, J., Chandelying, V., Sakondhavat, C., Bhiraleus, P., Rugpao, S., et al. (1998) Protection against Sexually Transmitted Diseases by Granting Sex Workers in Thailand the Choice of Using the Male or Female Condom: Results from a Randomized Controlled Trial. AIDS, 12, 1851-1859.

https://doi.org/10.1097/00002030-199814000-00017

[10] Sunanda, R., Mary, B., Caroline, M., Portia, M., Jo, D., Roderick, M., et al. (1995) Acceptability of the Female Condom in Zimbabwe: Positive But Male-Centred Responses. Reproductive Health Matters, 3, 68-79. https://doi.org/10.1016/0968-8080(95)90084-5

[11] Erica, L.G., Zena, S. and Wafaa, E. (1995) Short-Term Acceptability of the Female Condom among Staff and Patients at a New York City Hospital. Family Planning Perspectives, 27, 155-158. https://doi.org/10.2307/2136259

[12] National Agency for the Control of AIDS (2015) Nigeria Global AIDS Response Progress Report 2015.

[13] Avert. HIV and AIDS in Nigeria. http://www.avert.org/professionals/hiv-around-world/sub-saharan-africa/nigeria

[14] Okonko, I.O., Okerentugba, P.O., Adejuwon, A.O. and Onoh, C.C. (2012) Prevalence of Sexually Transmitted Infections (stis) among Attendees of Lead City University Medical Centre in Ibadan, Southwestern, Nigeria. Archives of Applied Science Research, 4, 980-987.

[15] Obiajuru, O.C. and Jude, N.O. (2007) The Prevalence of Sexually Transmitted Infections among Post-Primary and Tertiary School Students in Imo State, Nigeria. Nigerian Journal of Health and Biomedical Sciences, 6, 90-95. https://doi.org/10.4314/njhbs.v6i2.11651 
[16] Okonko, I.O., Akinpelu, A.O. and Okerentugba, P.O. (2012) Prevalence of Sexually Transmitted Infections (STIs) among Attendees of AFRH Centre in Ibadan, Southwestern Nigeria. Middle-East Journal of Scientific Research, 11, 24-31.

[17] Oyewole, I.O., Anyasor, G.N. and Michael-Chikezie, E.C. (2010) Prevalence of STI Pathogens in HIV-Infected and Non-Infected Women: Implications for Acquisition and Transmission of HIV in Nigeria. Asian Journal of Medical Sciences, 2, 163-166.

[18] Isiaka-Lawal, S.A., Nwabuisi, C., Fakeye, O., Saidu, R., Adesina, K.T., Ijaiya, M.A., et al. (2014) Pattern of Sexually Transmitted Infections in Human Immunodeficiency Virus Positive Women Attending Antenatal Clinics in North-Central Nigeria. Sahel Medical Journal, 17, 145-150. https://doi.org/10.4103/1118-8561.146820

[19] Balogun, T.M., Awofala, B., Iredu, I.C., Ajayi, A.O. and Ohakwere, M. (2013) Condom Use among Antiretroviral Therapy Naive People Living with HIV at a Tertiary Health Care Hospital in Lagos, Nigeria: Implication for Prevention of New Infections. Nigerian Quarterly Journal of Hospital Medicine, 23, 330-333.

[20] Tobin-West, C.I., Maduka, O., Onyekwere, V.N. and Tella, A.O. (2014) Awareness, Acceptability, and Use of Female Condoms among University Students in Nigeria: Implications for STI/HIV Prevention. International Journal of Adolescent Medicine and Health, 26, 259-265. https://doi.org/10.1515/ijamh-2013-0300

[21] Agbor, I.E., Etokidem, A. and Ugwa, E. (2017) Factors Responsible for Disclosure of HIV Seropositivity among Residents of Cross River State, Nigeria. Indian Journal of Community Medicine, 42, 138-142. https://doi.org/10.4103/ijcm.IJCM_313_15

[22] Kinuthia, J., et al. (2018) Prevalence and Correlates of Non-Disclosure of Maternal HIV Status to Male Partners: A National Survey in Kenya. BMC Public Health, 18, 671. https://doi.org/10.1186/s12889-018-5567-6

[23] Daskalopoulou, M., Lampe, F.C., Sherr, L., et al. (2016) Non-Disclosure of HIV Status and Associations with Psychological Factors, ART Non-Adherence, and Viral Load Non-Suppression among People Living with HIV in the UK. AIDS and Behavior, 21, 184-195. https://doi.org/10.1007/s10461-016-1541-4

[24] Adekanle, D.A., Olowookere, S.A., Adewole, A.D., Adeleke, N.A., Abioye-Kuteyi, E.A. and Ijadunola, M.Y. (2015) Sexual Experiences of Married HIV Positive Women in Osogbo, Southwest Nigeria: Role of Inappropriate Status Disclosure. BMC Women's Health, 15, 6. https://doi.org/10.1186/s12905-015-0164-7

[25] Ndinda, C., Chimbwete, C., McGrath, N. and Pool, R. (2007) MDP GROUP Community Attitudes towards Individuals Living with HIV in Rural Kwa-Zulu Natal, South Africa. AIDS Care, 19, 92-101. https://doi.org/10.1080/09540120600888378

[26] Liamputtong, P., Haritavorn, N. and Kiatying-Angsulee, N. (2009) HIV and AIDS, Stigma and AIDS Support Groups: Perspectives from Women Living with HIV and AIDS in Central Thailand. Social Science \& Medicine, 69, 862-868. https://doi.org/10.1016/j.socscimed.2009.05.040

[27] Painter, T.M. (2001) Voluntary Counseling and Testing for Couples: A High-Leverage Intervention for HIV/AIDS Prevention in Sub-Saharan Africa. Social Science \& Medicine, 53, 1397-1411. https://doi.org/10.1016/S0277-9536(00)00427-5

[28] World Health Organisation (2012) Guidance on Couples HIV Testing and Counselling Including Antiretroviral Therapy for Treatment and Prevention in Serodiscordant Couples: Recommendations for a Public Health. http://www.who.int/hiv/pub/guidelines/9789241501972/en

[29] Wikipedia (2012) Lagos. http://www.en.wikipedia.org/wiki/lagos

[30] Kalichman, S.C., Cherry, C., Kalichman, M.O., Washington, C., Grebler, T., Hoyt, G., Merely, C. and Welles, B. (2016) Sexual Behaviours and Transmission Risks 
among People Living with HIV: Beliefs, Perceptions and Challenges to Using Treatment as Prevevtion. Archives of Sexual Behavior, 45, 1421-1430. https://doi.org/10.1007/s10508-015-0559-4

[31] Nöstlinger, C., Nideröst, S., Gredig, D., Platteau, T., Gordillo, V., Roulin, C., Rickenbach, M., Dias, S.F., Rojas, D., the Swiss HIV Cohort Study and the Eurosupport Study Group (2010) Condom Use with Steady Partners among Heterosexual People Living with HIV in Europe: Testing the Information-Motivation-Behavioural Skill Model. AIDS Patient Care and STDs, 24, 771-780.

https://doi.org/10.1089/apc.2010.0246

[32] Nieves, C.I., Kaida, A., Seage III, G.R., Kabakyenga, J., Muyindike, W., Boum, Y., Rain Mocello, A., Martin, J.N., Hunt, P.W., Haberer, J.E., Bangsberg, D.R. and Matthews, L.T. (2015) The Influence of Partnership on Contraceptive Use among HIV Infected Women Accessing Antiretroviral Therapy in Rural Uganda. Contraception, 92, 152-159. https://doi.org/10.1016/j.contraception.2015.04.011

[33] Joshi, B., Velhal, G., Chauhan, S., Kulkami, R., Begum, S., Nandanwar, Y.S., Fonseca, M., Baweja, S., et al. (2015) Contraceptive Use and Unintended Pregnancies among HIV-Infected Women in Mumbai. Indian Journal of Community Medicine, 40, 168-173. https://doi.org/10.4103/0970-0218.158855

[34] Kimani, J., Warren, C., Abuya, T., Mutemwa, R., Mayhew, S. and Askew, I. (2015) Family Planning Use and Fertility Desires among Women Living with HIV in Kenya. BMC Public Health, 15, 909. https://doi.org/10.1186/s12889-015-2218-z 